Sign Systems Studies 49(1/2), 2021, 166-190

\title{
Metaphor, induction and innovation: Getting outside the box
}

\author{
Inesa Sahakyan ${ }^{1}$
}

\begin{abstract}
Today more than ever innovation seems vital for us to anticipate the future and adapt to our rapidly changing world. But what is innovation and how is it accomplished? How can the mind generate innovative ideas? To gain a better understanding of the mechanisms underlying the human capacity to innovate, the present study aims at answering two basic questions: first, 'what makes innovation possible?' and second, 'why are innovative ideas unusual?'. These questions are addressed within the framework of Peircean semiotics, in particular in the light of Peirce's conception of inference. Different types of inferences are studied to determine the mode of reasoning which is central to innovative thought. While creativity and innovation are often analysed through the prism of abduction, this study puts forward an alternative approach drawing a parallel between modes of inferences and types of hypoicons. It claims that what makes innovation possible is metaphoric reasoning underlying induction.
\end{abstract}

Keywords: creativity; innovation; induction; inference; metaphor; metaphorical reasoning

\section{Introduction}

The present paper aims at throwing light onto the mechanisms underlying the human capacity to innovate. To this end, it seeks answers to the following two questions: first, 'what makes innovation possible?' and second, 'why are innovative ideas unusual?'. Before addressing these research questions, a common ground needs to be reached as to what exactly innovation means. For a better understanding of what innovation is, it is useful to begin with determining what it is not. Innovation usually implies improvement, facilitation and enhanced efficiency in the accomplishment of everyday tasks in different domains of human activity. Consequently, more often than not the word 'innovation' is associated with

1 Department of Applied Foreign Languages, University of Grenoble Alpes, Grenoble, France; e-mail: inesa.sahakyan@univ-grenoble-alpes.fr. 
the domains of science and technology and is usually employed synonymously with 'scientific advancement and technological progress'. However, innovation has always been part of human activities in a wide range of domains, such as literature, architecture or music. Therefore, innovation should not be assimilated with technologically or digitally driven progress propelled by hard sciences. A literary or artistic creation, a marketing campaign, an architectural design and a musical performance can all be innovative in their marking a clear break with what was done before and thereby being novel in nature. Thus, innovation implies looking into the future, moving forward and making progress without necessarily being bound to pertain to science and technology.

The mention of the word 'innovation' also brings to mind the ideas of novelty, originality and creativity. Thus, innovation goes hand in hand with creativity and is intricately linked with it. But how do these two concepts relate to each other? Most business scholars distinguish between 'creativity' as the ideas or products generated by individuals, and 'innovation' as the successful execution of a new product or service by an entire organization (cf. Sawyer 2012 [2006]: 8). As Sawyer (2012[2006]: 7) explains, "The most basic requirement of a creative thought or action is that it must be novel or original". However, some personality psychologists hold that true creativity requires not only novelty but also appropriateness and usefulness (cf. Sawyer 2012[2006]: 9). In a similar stance, the Online Cambridge Dictionary $(2020)^{2}$ defines 'innovation' as “(the use of) a new idea or method".

Hence, the creativity theories developed throughout centuries fall into two major categories: idealist and action theories. While for the idealist theories the creative process is tantamount to the emergence of the creative idea - the moment of insight, for action theories the execution of the creative idea is key to the accomplishment of the creative process inasmuch as it implies the adaptation of the initial idea to the reality. This view of creativity is interesting in that it takes into account the physical world. As we see it, innovation is a change anticipated and conceived to serve a particular pragmatic purpose: that is, overcome a constraint, solve a problem or serve a use. Inasmuch as innovation draws on creative ideas, creativity is requisite for innovation. Thus, it could be stated that all innovation involves creativity, but not all creative ideas give rise to innovations. This leads us to the definition of innovation as applied creativity and of particular instances of innovations as multimodal embodiments of creative ideas.

2 Innovation. Meaning In: The Cambridge English Dictionary. [Online Dictionary.cambridge. org.] <https://dictionary.cambridge.org/dictionary/english/innovation> was accessed on 10 June 2020]. 
Yet how are creativity and innovation accomplished? As Sawyer (2012 [2006]: 7) puts it, "[c]reativity involves a combination of two or more thoughts or concepts that have never been combined before by that individual". The idea of combination is central to creativity and thereby to innovation. In this respect, Peirce's conception of inference is of particular use in shedding light onto the nature of innovative thought and the way it is accomplished. Peirce describes inference as having three essential steps - colligation, observation and judgement. Colligation or copulation consists in "bringing together certain propositions which we believe to be true, but which, supposing the inference to be a new one, we have hitherto not considered together, or not united in the same way" (CP 2.442). This definition is insightful as it helps discern the two facets of innovation - it being a matter of what and how. To put it differently, what characterizes innovation is, first, the fact of drawing parallels between phenomena or ideas that were not considered together before (what is brought together), and second, the way in which this is done (how). To be considered innovative, the colligation should be unprecedented. This is where imagination and creativity come in, for to be unprecedented these ways are to be imagined and created anew.

Can anyone be innovative or is it a unique quality of a genius mind? Creativity has long been thought of as a spiritual and mysterious gift given at birth, rather than a basic cognitive activity accessible to all. The ancient Greeks attributed creativity in arts, literature and science to the Muses - the inspirational goddesses. This brings us to the enquiries that constitute the focus of the present study: what makes creative ideas and, therefore, innovation possible and why are those ideas unique? These questions are addressed within the framework of Peircean semiotics.

In what follows I would like to argue that what makes innovation possible is a particular reasoning mechanism and what makes it so unique is the nature of such reasoning which requires making a leap from what is known. The discussion that follows is broken into three sections. The opening section examines the inner workings of reasoning. Argument being the basic constituent unit of reasoning, its functioning is analysed in Section 1.1 so as to contribute to our better understanding of reasoning mechanisms and their pre-eminence for innovative processes. Section 1.2 further explores the different kinds of arguments underlying distinct modes of reasoning with a special focus on the mode of representation involved in inferences. Finally, drawing on Peirce's principle of inclusiveness, an endeavour is made in Section 1.3 to trace the manifestation of likeness throughout the three modes of reasoning. As will be demonstrated, the mode of representation underlying reasoning mechanisms bears important implications for creative and innovative thinking. Based on arguments presented in Section 1, Section 2 argues 
for the need for a new perspective on metaphor, which would account not only for the latter's creative and innovative functions in language but also for its potential in developing ontological innovations. To do so, it presents a diachronic analysis of major theories of metaphor and an overview of issues that a new perspective on metaphor should address. Finally, the third and the last section endeavours to address the myths surrounding creativity and innovation and provide insight into why innovative ideas are unique. The paper ends with some concluding remarks.

\section{The inner workings of reasoning}

When involved in innovative processes, the mind carries out a conscious and controlled endeavour in which it seeks a solution to a real-life problem. Understanding how innovation is accomplished thus requires an insight into reasoning mechanisms. To study reasoning, we will first analyse its constituent elements before proceeding to the examination of distinct modes of reasoning.

\subsection{Argument - the mainstay of reasoning}

As a mode of thought, reasoning necessarily involves signs and the class of signs involved in reasoning is the argument - the sign of the highest complexity (cf. Peirce 1903). Throughout his writings Peirce employs the term 'argument' synonymously with 'inference' and defines it as "a body of premisses" (CP 2.461). Peirce (CP 2.309) also refers to argument as a triple sign to indicate its being constituted of premisses and a conclusion, which are, in fact, represented by propositions. Bringing together propositions is the departure point of all reasoning. As Peirce (CP 2.442) explains:

The first step of inference usually consists in bringing together certain propositions which we believe to be true, but which, supposing the inference to be a new one, we have hitherto not considered together, or not as united in the same way. This step is called colligation.

Inasmuch as the proposition is thought of as a mode of assertion, "the compound assertion resulting from colligation is a conjunctive proposition, that is, it is a proposition with a composite icon, as well as usually with a composite index" (CP 2.442). Peirce (CP 2.470) claims that the complex nature of the icon involved in an inference is not due to the number of premisses constituting the argument as "[e]very argument of more than two premisses can be resolved into a series of 
arguments of two premisses each". Furthermore, "[a]n inference [...] may have but a single premiss [...] But even if there be but one premiss, the icon of that proposition is always more, or less complex" (CP 2.443). To conclude, argument or inference is comprised of one or more premisses and necessarily involves a conclusion. All the constituent elements of the argument are represented by propositions, which, when brought together, form a colligation - the first and the most difficult step of an argument.

To constitute the premisses of an argument, propositions are brought together based on a feature common to both of them. In other words, propositions relate to each other through resemblance or similarity, which renders their relation iconic. And, as Peirce (CP 2.444) puts it, "whenever one thing suggests another, both are together in the mind for an instant" - the two icons are, thus, together instantly present in the mind. Together, the propositions of the argument form a colligation which is a complex icon and which is central to the act of inference. Let us consider, for instance, the following example of argument studied by Peirce (CP 2.623):

Premiss 1 - All the beans from this bag are white.

Premiss 2 - These beans are from this bag.

Conclusion - These beans are white.

Here Premisses 1 and 2 are icons of each other inasmuch as the former represents the latter through resemblance, by virtue of sharing a common feature with it that of belonging to "this particular bag".

The colligation is followed by a step in which the complex icon of the inference suggests another through observation of a certain feature of it. As Peirce (CP 2.443) explains:

The next step of inference to be considered consists in the contemplation of that complex icon, the fixation of the attention upon a certain feature of it, and the obliteration of the rest of it, so as to produce a new icon.

The particular conjunction created between the two icons, one suggesting the other, while at the same time involving this other, determines the third and the last step of the inference.

Hence the mind is not only led from believing the premiss to judge the conclusion true, but it further attaches to this judgment another - that every proposition like the premiss, that is having an icon like it, would involve, and compel acceptance of, a proposition related to it as the conclusion then drawn is related to that premiss. (CP 2.444) 
The term 'like' expresses the idea of resemblance constituting the essence of an icon. This final step of the inference thus consists in a special judgment through resemblance, i.e. a judgment based on an icon.

To conclude, the argument, or inference, is a complex element of thought comprised of one or more premisses and a conclusion that are represented by propositions. The act of inference is realized in three steps, which can be referred to as the elements of inference: "The three essential elements of inference are, then, colligation, observation, and the judgment that what we observe in the colligated data follows a rule" (CP 2.444).

The argument being the basic constituent unit of reasoning, the trichotomy of arguments introduced by Peirce in 1903, including abduction, deduction and induction, determine the three modes of reasoning, abductive, deductive and inductive, respectively. These are analysed in the following section so as to determine the mode of reasoning, which is central to innovative thinking.

\subsection{The trichotomy of arguments and the three modes of reasoning}

In what follows, the three modes of reasoning are analysed with a focus on the mode of representation underlying them.

\subsubsection{Originary argument and abductive reasoning}

Abduction is a mode of reasoning which consists in adopting provisional hypotheses by means of forming general propositions. It is this mode of reasoning that is involved in starting new ideas, and this feature accounts for the second term employed by Peirce to refer to abduction, namely, 'originary argument' (cf. CP 2.96). To gain insight into the nature of originary argument and the inner structure of abductive reasoning, let us consider the following example of an abductive inference as studied by Peirce (CP 2.623):

Premiss 1 (Rule): All the beans from this bag are white.

Premiss 2 (Result): These beans are white.

Conclusion (Case): These beans are from this bag.

The conclusion of abductive reasoning is a general prediction bearing on a particular case. As we can see, the colligation between premisses is realized based on their sharing a common feature - the colour white. Consequently, the facts of the premisses constitute an Icon of the fact drawn in the conclusion. This iconic relation governing the abductive argument is put forward by Peirce (CP 2.96) in the following definition: 
An originary Argument, or Abduction, is an argument which presents facts in its Premiss which present a similarity to the fact stated in the Conclusion, [...] so that we are not led to assert the Conclusion positively but are only inclined toward admitting it as representing a fact of which the facts of the Premiss constitute an Icon.

Key among the ideas suggested in the above definition is that, first, the relation between the facts stated in the premiss and the one drawn in the conclusion of the abductive argument is that of resemblance. Second, being represented by an icon, which, by definition, does not afford positive assertion of the true existence of the represented object, the conclusion of the abduction cannot be asserted positively. It is a mere hypothesis in need of verification in the future (CP 2.270). Therefore, the fact in the conclusion, i.e. 'these beans are from this bag', is but a hypothesis which can as well fail to be true.

The mode of reasoning that has a higher complexity than abduction and thereby involves the latter is deduction, which is analysed in the section that follows.

\subsubsection{Obsistent argument and deductive reasoning}

To begin with, Peirce (CP 2.96) defines deduction as:

an argument representing facts in the Premiss, such that when we come to represent them in a Diagram we find ourselves compelled to represent the fact stated in the Conclusion; [...] that is to say, the Conclusion is drawn in acknowledgment that the facts stated in the Premiss constitute an Index of the fact which it is thus compelled to acknowledge. [emphasis added, I. S.]

Furthermore, the term 'Obsistent' is employed by Peirce to characterize deduction. Peirce's terminology is quite remarkable in that his terms throw light on the essence of the notions underlying them. Thus, Peirce (CP 2.96) explains that "Deduction is Obsistent in respect to being the only kind of argument which is compulsive". That is, the facts represented in the premiss necessarily lead to the fact stated in the conclusion. This compulsive and obsistent relation can be accounted for by the mode of representation involved. In particular, the fact that constitutes the conclusion of a deductive argument is represented by the facts in the premiss through contiguity. Therefore, the facts stated in the premiss constitute an index of the fact drawn in the conclusion. To gain a better understanding of the mode of reasoning underlying deduction, let us consider the following example as suggested by Peirce (CP 2.623): 
Premiss 1 (Rule): All the beans from this bag are white.

Premiss 2 (Case): These beans are from this bag.

Conclusion (Result): These beans are white.

Here Premiss 1 is represented by a proposition that has as its subject the collective total of the beans ('all the beans'). The two basic qualities that are predicated of it are its 'pertinence to this particular bag' and the 'possession of whiteness'. Premiss 2 has 'these beans' as its subject, which is predicated of one quality - 'pertinence to this bag. The two propositions are related to each other in that they share a common feature - 'the pertinence to this bag. This relation is contiguous inasmuch as they both belong to the same physical space - 'this bag. Hence, a hypothesis is formed according to which all the qualities predicated of the subject of the first proposition are predicable of the subject of the second one. Such reasoning leads to the conclusion that 'these beans are white.' Thus, the conclusion of deduction bears on a set of qualities (Qualisigns) predicable of a particular case through contiguity.

\title{
1.2.3. Transuasive argument and inductive reasoning
}

Finally, the third and the last kind of argument called 'induction' is defined by Peirce (CP 2.96) as follows:

\begin{abstract}
A Transuasive Argument, or Induction, is an Argument which sets out from a hypothesis, resulting from a previous Abduction, and from virtual predictions, drawn by Deduction, of the results of possible experiments, and having performed the experiments, concludes that the hypothesis is true in the measure in which those predictions are verified, this conclusion, however, being held subject to probable modification to suit future experiments. [Emphasis added, I. S.]
\end{abstract}

By inductive reasoning, Peirce means 'a course of experimental investigation' (cf. CP 5.168). Induction is the most complex kind of argument, which involves abduction and deduction. Its conclusion is a hypothesis. However, unlike abduction, which equally involves a hypothesis as its conclusion and which refers to a particular case that has occurred in the present, the hypotheses drawn through induction are of general nature and refer to the future in that they apply to any particular case that can occur in the future.

Induction is where we generalize from a number of cases of which something is true, and infer that the same thing is true of a whole class. Or, where we find a certain thing to be true of a certain proportion of cases and infer that it is true of the same proportion of the whole class. (CP 2.624) 
Induction is equally named 'transuasive' "in respect to its alone affording us a reasonable assurance of an ampliation of our positive knowledge" (CP 2.96). Indeed, this kind of argument enables us to amplify the knowledge built on the past experience by extending it so as to involve the future experience, and such ampliation is rendered possible through the process of 'virtual prediction', which is accounted for by Peirce (CP 2.96) in the following:

By the term "virtual prediction," I mean an experiential consequence deduced from the hypothesis, and selected from among possible consequences independently of whether it is known, or believed, to be true, or not; so that at the time it is selected as a test of the hypothesis, we are either ignorant of whether it will support or refute the hypothesis, or, at least, do not select a test which we should not have selected if we had been so ignorant.

As far as the mode of representation in an inductive inference is concerned, the fact drawn in the conclusion is represented through convention or law inasmuch as the facts stated in the premiss constitute the symbol of the conclusion as Peirce (CP 2.96) explained in the following:

Since the significance of the facts stated in the premisses depends upon their predictive character, which they could not have had if the conclusion had not been hypothetically entertained, they satisfy the definition of a Symbol of the fact stated in the conclusion.

This is the case in the following example of inductive argument (CP 2.623):

Premiss 1 (Case): These beans are from this bag.

Premiss 2 (Result): These beans are white.

Conclusion (Rule): All the beans from this bag are white.

As we can see, the conclusion is drawn through convention, i.e. by adopting a general rule or law that a quality that is predicated of a number of individual instances in a particular case can, through extension, be predicable of other instances. This comes to adopting a general hypothesis.

Unlike the deductive mode of reasoning, which, as we saw earlier, is the mere application of a general rule to a particular case, Peirce explains that the inductive or 'synthetic reasoning' is something more than the mere application of a general rule to a particular case (cf. CP 2.620). If in case of deductive reasoning the observer is aware of a general rule applicable to particular cases, in case of induction no such rule is present in the observer's mind. Instead, if not knowing what proportion of white beans there is in the bag, the observer draws a handful at 
random and finds out that two thirds of the beans in the handful sample are white, he will conclude that about two thirds of those in the bag are white, that is, he will conclude a rule from the observation of a result in a certain case (cf. CP 2.622). This points to the essence of induction, namely, that of affording the inference of a rule. The conclusion of abduction being a 'Case' and that of deduction a 'Result', induction, thus, is the only mode of reasoning which yields a 'Rule'.

To conclude, the following table is constituted to give a summary overview of the basic features of the trichotomy of arguments examined above and the mode of representation of their inferences:

Table 1. Trichotomy of arguments.

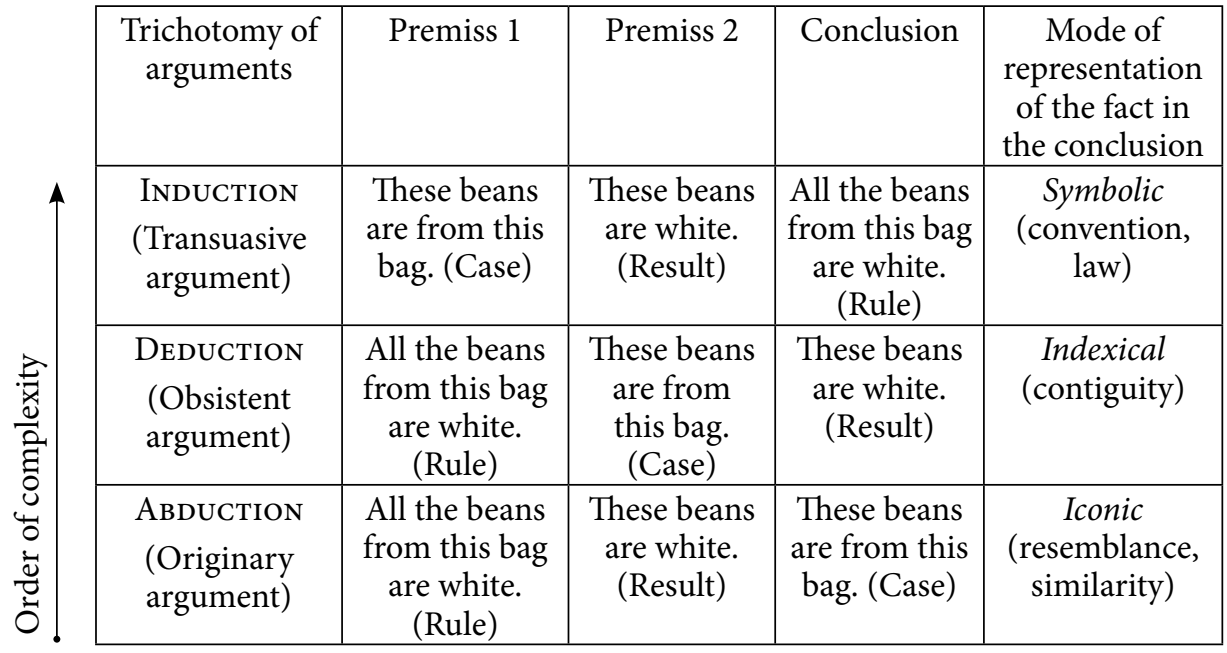

Examining the mode of representation involved in arguments, Peirce explains (cf. CP 2.96) that the principle of the growing complexity is applicable to it. That is, the facts in the major premisses represent the fact in the conclusion through resemblance, physical contiguity and convention in abductive, deductive and inductive arguments, respectively (see Table 1). In other words, the facts stated in the premisses constitute an icon, an index and a symbol of the fact in the conclusion in abduction, deduction and induction, correspondingly. In the examples discussed above, the symbol of the fact stated in the conclusion of an inductive argument involves an index and an icon that, in this particular case, is expressed through the contiguity of beans belonging to the same bag and their resemblance in sharing a common quality - whiteness. 
According to Peirce's principle of inclusiveness of hierarchically related signs, all the three kinds of arguments involve an icon. This idea can be represented as follows:

\author{
Abduction involves an (Icon) \\ Deduction involves an (Index [Icon]) \\ Induction involves a (Symbol (Index [Icon] $)$ )
}

Hence, the iconic mode of representation or likeness manifests itself throughout the three modes of reasoning discussed above. Indeed, the iconic mode of representation is fundamental to reasoning as it is requisite to inference, which consists in drawing a conclusion upon premisses through a judgment based on resemblance (cf. CP 2.444). In particular, through the observation of the colligated data (propositions brought together as premisses), a conclusion is drawn based on the judgment of resemblance between the facts involved in Premiss 1 and Premiss 2.

With regard to the notion of likeness underlying icons, Peirce notes that it consists in the sign's sharing some common features with its object (cf. CP 2.276). According to the nature of likeness, which can be based on simple qualities, analogous relations, or parallelism, Peirce distinguishes three kinds of icons, which he calls hypoicons: namely, images, diagrams and metaphors, respectively (cf. $\mathrm{CP}$ 2.277). Given that the iconic mode of representation underlies all the three modes of reasoning and that there are three kinds of icons the question that comes forward is 'what is the kind of hypoicon involved in each kind of argument?' Addressing this question will enable us to demonstrate the central role of one particular hypoicon (metaphor) and the mode of reasoning it underlies (induction) in innovative processes. This task is addressed in the following section.

\title{
1.3. Manifestations of likeness in abduction, deduction and induction
}

As far as deductive argument is concerned, Peirce treated the question extensively (cf. CP $2.96 ; 2.267 ; 5.162$ ). However, he provided no treatment of likeness in abductive and inductive reasoning.

\subsubsection{Likeness in abduction}

As discussed above, the conclusion of an abductive argument is reached through a judgment bearing on the existence of an iconic relationship - a resemblance between a general rule (All the beans from this bag are white) and a specific result (These beans are white). Here the premisses of the argument, the rule 
and the result, resemble each other by virtue of sharing some simple qualities (qualisigns, here, whiteness). Therefore, it could be stated that the kind of likeness involved in abduction is characteristic of the simplest kind of hypoicon - the image. Furthermore, "since a quality is a mere logical possibility, it can only be interpreted as a sign of essence, that is, as a Rheme" (CP 2.254). As Peirce (CP 2.250) explains:

A Rheme is a Sign which, for its Interpretant, is a Sign of qualitative Possibility, that is, is understood as representing such and such a kind of possible Object. Any Rheme, perhaps, will afford some information; but it is not interpreted as doing so. (Emphasis added, I. S.)

The term 'possibility' is emphasized for it is key to understanding the nature of the information carried by rhemes. Inasmuch as the interpretant of a rheme represents it as a mere possibility, rhemes lack an assertive value. Thus, abduction being based on images, the simplest kind of hypoicons, its conclusion is rhematic and cannot be asserted positively (cf. CP 2.96).

\subsubsection{Likeness in deduction}

As explained by Peirce (CP 3.363), all deductive reasoning is diagrammatic since the kind of resemblance involved in it is of the nature of analogous relations. In more specific terms,

deduction consists in constructing an icon or diagram the relations of whose parts shall present a complete analogy with those of the parts of the object of reasoning, of experimenting upon this image in the imagination, and of observing the result so as to discover unnoticed and hidden relations among the parts. (CP 3.363)

Thus, the kind of hypoicon involved in deduction is the diagram. Finally, the next section examines the kind of likeness manifesting itself in induction. Close attention is paid to this mode of reasoning, since, as will be argued, inductive reasoning is key to innovative thought.

\subsubsection{Likeness in induction}

In an inductive argument the colligated data is constituted of a particular case ('These beans are from this bag') and a result ('These beans are white'). Through observation and judgment of resemblance, a rule is inferred ('All the beans from this bag are white'). Here the inference is based on parallelism between a particular case and a general category. The judgment is made based on a resemblance between a particular instance of a phenomenon at present (Case), and all the phenomena pertaining to that category in general (inference of a Rule). 
Therefore, the kind of likeness manifesting itself in induction is based on drawing a parallel between two otherwise unrelated situations, the present and the future, a particular case and a general category. And the only hypoicon which affords establishing likeness through parallelism is the metaphor. Therefore, I would like to argue that the iconic mode of representation underlying induction is based on metaphorical representation.

The above discussion leads us to the conclusion that with regard to the mode of iconic representation manifesting itself in different arguments a parallel can be drawn between the triad of hypoicons and the trichotomy of arguments, thereby modes of reasoning, as follows. Firstly, in abduction, which is the mode of reasoning of the lowest complexity, iconic representation partakes of the nature of simple qualities; therefore, the kind of likeness involved in it is characteristic of the image. Secondly, deductive reasoning involves the diagram since its inference is based on a judgement of resemblance that partakes of the nature of analogous relations. Finally, within the kind of argument of the highest complexity, i.e. induction, the fact in the major premiss being the symbol of the fact in the conclusion, represents it through convention, and the conventional relation (symbolic representation) equally involves a relation of contiguity (an index) as well as that of resemblance (an icon). The kind of icon involved in the inductive argument is the hypoicon of the highest complexity - the metaphor. Thus, abduction, deduction and induction involve the image, diagram and metaphor, respectively.

The idea that the metaphorical mode of representation underlies induction calls for a shift in perspective on it. Metaphor is not a pure icon, whose mode of representation is only based on resemblance. As Anderson (1984: 457) explains "the parallelism of a metaphor, in being between "other" mediums, is between things which are not, or cannot be, isomorphically related". Thus, the parallelism established by metaphor is conventional and, in this, metaphor satisfies the definition of a Symbol.

Peirce's idea of metaphor is difficult to grasp and account for since there are very few instances of the term in his writings. Though Peirce places metaphor in the class of icons, in one of his definitions of the symbol he notes: "Every symbol is, in its origin, either an image of the idea signified, or a reminiscence of some individual occurrence, person or thing connected with its meaning or is a metaphor" (CP 2.222, 1903). As the definition derives from his later writings, we can see a growth of Peirce's conception of the function of metaphor, in which he acknowledges the conventional mode of representation involved in metaphor. Indeed, by calling metaphor a symbol, Peirce holds metaphors as thirds, therefore involving Mediation. In the light of Peirce's later arguments, Anderson (1984: 456) defines metaphor as "a symbol whose iconicity dominates". This view of metaphor 
as a symbol further grounds the idea that metaphoric representation underlies inductive reasoning, which is based on convention. Furthermore, it is in line with Peirce's qualification of the premisses of an inductive inference as symbols of the fact stated in the conclusion (CP 2.96).

This understanding of metaphor throws light on its inner complexity. Underlying induction, metaphor, thus, is a mode of reasoning of the highest complexity, which affords inferring a rule by drawing parallels between otherwise unrelated domains and phenomena. I would like to argue that the mind's capacity to generate innovative ideas, which actually consists in making unprecedented combinations of ideas, is made possible by metaphoric representation and inductive reasoning.

\section{The creative and innovative functions of metaphor}

\subsection{Major theories of metaphor}

Since Aristotle introduced the term 'metaphor' in his Poetics in the Fourth Century B.C., a number of theories have been developed to throw light on the nature of metaphor. Table 2 provides a diachronic overview of major existing theories of metaphor:

Table 2. Diachronic overview of major theories of metaphor.

\begin{tabular}{|l|l|l|l|}
\hline \multicolumn{1}{|c|}{ Theory Name } & \multicolumn{1}{c|}{ Origin } & Function of metaphor & \multicolumn{1}{c|}{ Basic features } \\
\hline $\begin{array}{l}\text { Comparison } \\
\text { theory, "similarity } \\
\text { view" }\end{array}$ & $\begin{array}{l}\text { Aristotle (4th } \\
\text { century B.C.) }\end{array}$ & $\begin{array}{l}\text { - rhetorical/ } \\
\text { ornamental }\end{array}$ & $\begin{array}{l}\text { - The features being compared pre- } \\
\text { existed the use of the metaphor. } \\
\text { - Metaphor is seen as an analogy. }\end{array}$ \\
\hline $\begin{array}{l}\text { Interaction } \\
\text { theory }\end{array}$ & $\begin{array}{l}\text { I. A. Richards } \\
\text { (1936) }\end{array}$ & $\begin{array}{l}\text { - creating similarity } \\
\text { - affecting the ways } \\
\text { we perceive and } \\
\text { conceive of the world }\end{array}$ & $\begin{array}{l}\text { - The use of the metaphor creates } \\
\text { the similarity. }\end{array}$ \\
& & $\begin{array}{l}\text { There is a mutual transfer } \\
\text { (interaction) of features } \\
\text { between the two elements } \\
\text { of a metaphor ("subsidiary } \\
\text { subject")"vehicle" and "principal } \\
\text { subject"/"tenor"). }\end{array}$ \\
& & $\begin{array}{l}\text { "Subsidiary subject" is used to } \\
\text { foster insight into a "principal } \\
\text { subject". }\end{array}$ \\
\hline
\end{tabular}




\begin{tabular}{|c|c|c|c|}
\hline Theory Name & Origin & Function of metaphor & Basic features \\
\hline Pragmatic theory & $\begin{array}{l}\text { D. Davidson } \\
(1978) \\
\text { J. Searle } \\
(1979)\end{array}$ & $\begin{array}{l}\text { - suggesting/implying } \\
\text { meaning }\end{array}$ & $\begin{array}{l}\text { - A distinction is made between } \\
\text { "word, or sentence meaning" } \\
\text { (literal meaning) and a speaker's } \\
\text { "utterance meaning" (the } \\
\text { metaphorical meaning that a } \\
\text { speaker intends to convey). } \\
\text { - The literal statement is used in } \\
\text { such a way as to suggest or imply } \\
\text { meaning. } \\
\text { - The speaker's intention and } \\
\text { the context of utterance are } \\
\text { considered as key. }\end{array}$ \\
\hline $\begin{array}{l}\text { Conceptual } \\
\text { Metaphor Theory } \\
\text { (CMT), cognitive } \\
\text { view }\end{array}$ & $\begin{array}{l}\text { G. Lakoff and } \\
\text { M. Johnson } \\
(1980) \\
\text { G. Lakoff and } \\
\text { M. Turner } \\
(1989) \\
\text { G. Lakoff } \\
(1993)\end{array}$ & $\begin{array}{l}\text { - cognitive function } \\
\text { - structuring our } \\
\text { perception }\end{array}$ & $\begin{array}{l}\text { - Metaphor is conceived of as a } \\
\text { projection or mapping across } \\
\text { "conceptual domains" ("source } \\
\text { domain" and "target domain"). } \\
\text { - When using a metaphor, part of } \\
\text { the conceptual structure of the } \\
\text { "source domain" is "mapped" } \\
\text { onto the conceptual structure } \\
\text { of "target domain", in a one-way } \\
\text { "transaction" (as distinct from an } \\
\text { "interaction"). }\end{array}$ \\
\hline
\end{tabular}

A more recent framework related to Conceptual Metaphor Theory (CMT) is the Conceptual Blending (or Integration) Theory (BT) (cf. Fauconnier 1985, 1997; Fauconnier, Turner 1998, 2002) which also adopts a conceptual perspective on metaphor. This framework suggests complex schemata to account for the intricate processes of meaning making. Despite their differences, both CMT and BT explore metaphor as a tool for the conceptual analysis of language.

Strongly influenced by CMT, new embodied-cognition (Bergen 2012) and discourse-oriented (cf. Casasanto, Boroditsky 2008; Landau, Robinson, Meier 2014) approaches to metaphor have emerged. These come under social and cognitive psychology perspectives whose purpose is to explore the tacit influence of conceptual metaphor on people's non-linguistic cognitive behaviour.

Put in broad terms, research on metaphor falls into two major categories: communicative-oriented or cognitive-oriented approaches. As Table 2 shows, so far metaphor has been seen as serving either communicative or cognitive purposes: that is, accomplishing a rhetorical function to reinforce the communicative message or affecting the ways in which we perceive and conceive of the world and phenomena (CMT). Unlike those theories, the present study aims at putting 
forward and arguing for the potential of metaphor, as a reasoning mechanism, to generate ontological innovations.

\subsection{Towards a new perspective on metaphor}

By putting forward the innovative power of metaphor, the present study aims at laying the foundations of a new perspective on metaphor that lies within a broader cognitive-oriented approach and aims at studying the role of metaphor and metaphorical reasoning in people's non-linguistic cognitive activities. The ideas of metaphor and creativity have already been associated in the past (cf. Black 1962; Loewenberg 1978; Miller 1996; Sanchez-Ruiz et al. 2013, just to mention a few). In his Models and Metaphors, Black (1962:37) points to the metaphor's capacity to create similarity. This view on metaphor serves as a basis for his interaction theory. Already in his 1976 book The Metaphoric Mind: A Celebration of Creative Consciousness, Bob Samples points to the realm of creativity that metaphors can entail. Also, studying personality traits of expert and novice scientists, Feist (1999) found that "the experts build models that make use of analogy, metaphor, and visual imagery" (cited in Sawyer 2012 [2006]: 273). Similarly, Casakin (2007, 2013) emphasizes the role of metaphors in design creativity. Studying metaphor, Anderson (1984: 465) also points to its role in artistic creativity, while Loewenberg (1978) addresses metaphor's creativity in fiction. However, it could be stated that the relations between metaphor and ontological innovation remain an underresearched area inasmuch as these studies do not point to a direct link between innovation (other than related to language, such as semantic innovation) and metaphor. This lack of consideration of the role of metaphor in innovative processes beyond language calls for a new perspective on it. The features of this new perspective are explicated in the next section.

\subsection{The creative and innovative metaphor}

Unlike major theories of metaphor developed so far, the new perspective I would like to put forward views metaphor as a reasoning mechanism which lies at the heart of creative and innovative processes. It allows the mind to generate novel combinations of ideas and thereby innovate and bring change into the world. The term 'metaphorical reasoning' is preferred to 'metaphorical thinking' based on the distinction that Peirce makes between controlled and uncontrolled thought (CP 2.26). Innovative thinking is a controlled problem-solving mental task; thereby it is appropriate to refer to it as reasoning proper. But how is innovation accomplished based on metaphorical reasoning? 
When confronted with a real-life problem, the mind seeks a solution. Where ordinary combinations of ideas available in and pertaining to the domain in which the problem has arisen provide no solution, the mind is compelled to look for one elsewhere, that is to say, in different, unusual and unrelated domains. This is where metaphor comes in. This mental leap from one domain to another, the unprecedented parallel between unrelated domains of practice is afforded by metaphor and the mode of reasoning underlying it. The quality set of one domain of practice, including physical features and systems of relations, is virtually predicted of phenomena in another domain and an innovative phenomenon is created. For a better understanding of this conceptual model of innovation based on metaphor, let us consider some recent examples of innovation.

In early 2020 the world was struck by the COVID-19 pandemic which put to the test the healthcare systems and resources of many countries throughout the world. As the virus attacked people's immune and respiratory systems, artificial respirators were used to help sick people breathe. The major problem that healthcare systems were confronted with was a huge shortage of such equipment as many hospitals suffered from a dire shortage of artificial respirators even in the most developed countries. The world's engineers were thus confronted with a real-life pragmatic problem - providing as many artificial respirators as necessary. However, since the demand was high and urgent, and conventional solutions, such as producing the necessary number of respirators failed to resolve the problem, engineers turned for solutions elsewhere. Thus, a parallel was drawn between two unrelated domains of practice, health care and diving. By drawing such an unprecedented parallel, Italian engineers turned snorkelling masks into life-saving ventilators ${ }^{3}$, thereby creating an innovative product.

Another example of innovation based on metaphoric reasoning is the use of medical or alternative face masks as an advertising space. As wearing masks became obligatory, some companies ordered masks for their employees. But what was particular about those masks is that they bore company logos on them. Thus, masks were used for marketing purposes. Such use of masks was innovative in that not only did it serve health purposes, but also a marketing one. In this example, a parallel is drawn between healthcare system and advertising and the use of a mask as an advertising space is innovative.

Finally, in this last example of innovation, the concept of "Lab Drive" was created during the 2020 COVID-19 pandemic. To avoid human contact and thereby the propagation of the virus, medical laboratories created a drive service for their

3 Isinnova, "Emergency mask for hospital ventilators", https://www.isinnova.it/easy-covid19eng/, was accessed on 25 May, 2020. 
labs. In this innovative system the patient replaces the client and the delivered product/service is no longer food but a laboratory screening test. It is the system of relations that is transferred from one domain into another through deduction; however, it is based on induction that an unprecedented parallel is drawn between two otherwise unrelated domains (fast food industry and health care) in the first place in order to create a new concept and service.

These examples of innovation point to the central role of metaphor in innovative thinking and its undeniable innovative potential, which the present study argues for. Furthermore, they demonstrate the fact that innovative ideas are but novel combinations of existing ones. In a similar stance, the psychologist Alexander Bain (1818-1903) first argued that "new combinations grow out of elements already in the possession of the mind" (in Sawyer 2012 [2006]: 8). Indeed, there is something profoundly curious and somewhat paradoxical about the idea of innovation. Although it implies novelty and originality, it undeniably departs from pre-existing ideas, which have simply been combined in unprecedented ways. This brings us to our second question, which has still remained unanswered, namely, 'why are innovative ideas unique?' This question is dealt with in the next section.

\section{Cognition, intuition, innovation}

If the mind is endowed with the capacity to generate innovative ideas, why are those ideas described as breakthrough, original or unique? Where does the myth on the mysterious nature of creative processes come from?

\subsection{Thinking inside the box: Cognition}

Thinking is a continuous process, which is based on semiosis - the continuous and infinite action of signs. Considering the activity of the mind, i.e. thought, two distinct factors governing the operation of thought should be taken into account. Firstly, and most importantly, mental action is guided by the information made available to the mind by the senses through what Peirce calls 'collateral experience' (cf. CP 8.183). Our experience consists in a continuous reaction of the self with the outside world, which is made of 'hard facts'. As Peirce (CP 1.324) explains, it is this kind of experience that governs our thought:

We are continually bumping up against hard fact. We expected one thing, or passively took it for granted, and had the image of it in our minds, but experience forces that idea into the background, and compels us to think quite differently. 
Thus, the course of our thought is determined by the experience of 'hard facts' inasmuch as "when anything strikes upon the senses, the mind's train of thought is always interrupted" (CP 1.431). Nonetheless, in the absence of any outward impressions, the thought is governed internally by the existent or newly generated ideas (i.e. thoughts), which are brought together through the laws of association and inference. And this is the second principle governing our thought:

In the absence of external impressions, thoughts chase one another through the mind in a sort of Bacchic train. Each suggests another. After a while, the clear train of thought is broken, the ideas remain scattered for a time, and then reconcentrate in another train. Psychologists recognize that the suggestion of one idea by another may take place according to either one of two different principles; for an idea may suggest another like it, or it may suggest another which has been connected with it in experience. (CP 7.451)

Psychologists refer to this phenomenon as 'association'. Peirce (CP 7.453) claims that association is the only force existing within the intellect, which has the power of controlling thoughts. Furthermore, Peirce accounts for the continuity of the mental operation in terms of inference, which associates ideas by relating judgments: "[...] the association of ideas consists in this, that a judgment occasions another judgment, of which it is the sign. Now this is nothing less nor more than inference" (CP 5.307). It could therefore be concluded that inference underlies all reasoning, which is a continuous process based on the association of ideas or thoughts.

As discussed above, the association of ideas may be realized either through resemblance, contiguity or convention. Peirce (CP 7.452) explains that the "association by contiguity as it is called, is the more typical" (emphasis added, I. S.). Thus, the association of ideas realized through contiguity is what best characterizes ordinary or 'typical' thinking. Peirce (CP 2.3) accounts for our faculty of reasoning as a natural instinct as follows:

We all have a natural instinct for right reasoning, which, within the special business of each of us, has received a severe training by its conclusions being constantly brought into comparison with experiential results. Nay, we not only have a reasoning instinct, but [...] we have an instinctive theory of reasoning, which gets corrected in the course of our experience. So, it would be most unreasonable to demand that the study of logic should supply an artificial method of doing the thinking that his regular business requires every man daily to do.

Peirce explains that we conduct a large amount of reasoning daily, and our ability to reason constitutes a congenital faculty of the mind, an innate awareness of a 
theory of logic that the scholastics called the reasoner's logica utens (cf. CP 2.186). The important point to note here is that our innate faculty of reasoning is trained throughout our experience. That is, our logica utens is constantly adapted to our experiential results, our previous knowledge. In this regard, Peirce suggests drawing a distinction between cognition, which has been built on previous cognition and intuition, as a kind of cognition, determined not by previous cognitions but by the transcendental object:

Throughout this paper, the term intuition will be taken as signifying a cognition not determined by a previous cognition of the same object, and therefore so determined by something out of the consciousness. Let me request the reader to note this. Intuition here will be nearly the same as "premiss not itself a conclusion"; the only difference being that premisses and conclusions are judgments, whereas an intuition may, as far as its definition states, be any kind of cognition whatever. But just as a conclusion (good or bad) is determined in the mind of the reasoner by its premiss, so cognitions not judgments may be determined by previous cognitions; and a cognition not so determined, and therefore determined directly by the transcendental object, is to be termed an intuition. (CP 5.213)

Drawing on Peirce's quote, I would like to put forward the idea that typical thinking, based on association of ideas by contiguity and governed by cognition (or knowledge, cf. CP 5.605), as opposed to intuition, is what best characterizes ordinary thinking and accounts for the uniqueness of innovative thought. This kind of 'typical' thinking is considered to be ordinary and can be referred to as 'thinking inside the box. The box metaphor is employed to refer to barriers and frontiers created by laws of association, judgments and previous cognition, which govern our everyday thinking. This kind of 'ordinary' and 'typical' thinking is opposed to innovative thinking, which requires getting outside the box.

\subsection{Getting outside the box: Intuition}

The notion of intuition being "cognition not determined by a previous cognition" (CP 5.213) is central to drawing unprecedented parallels, making novel combinations of ideas and thereby being innovative. Intuition is also requisite for inductive reasoning, whose inferences, as demonstrated above, represent the conclusion not through contiguity but through convention. The central role of intuition and inductive reasoning in innovative processes is also pointed out by Sawyer (2012[2006]: 371). In his work on the science of human innovation, Sawyer (2012 [2006]: 371) enquires into the nature of science. Are scientists creative or do they simply discover truths by observing the world and using deductive 
reasoning? Sawyer (2012[2006]) argues that scientists do not always proceed by deduction; they often proceed by induction, starting from a theory and then designing an experiment to see if the theory is supported by reality. To ground his argument, he refers to Albert Einstein's general theory of relativity and explains that Einstein's hypothesis was based on his intuitions and not on previous knowledge or experiential results (cognition). "Einstein wasn't just copying the reality when he created his theory. When scientists use induction instead of deduction, they're undeniably creative" (Sawyer 2012[2006]: 372).

A famous quote often attributed to Einstein also opposes intuitive and rational thinking, underlining the value of the former: "The intuitive mind is a sacred gift and the rational mind is a faithful servant. We have created a society that honours the servant and has forgotten the gift." Even though rational thinking is requisite for human cognitive activities, the value of intuitive thinking should not be ignored. Thus, creative and innovative thinking requires going beyond cognition determined by a previous cognition. Metaphor enables the mind to break the typical thinking process based on associations of ideas by contiguity and, instead, make novel combinations of ideas through convention. Thus, metaphor helps trespass the laws of association, break the barriers built by previous cognition and thus get outside the box.

To stimulate creative thinking, methods such as Creative Problem Solving (CPS) (cf. Osborn 1942; 1953) or Design Thinking (cf. Brown 2009; Kelley, Kelley 2013) resort to techniques which aim at helping participants generate as many divergent and unusual ideas as possible. These methods of creativity are based on carefully designed tools and activities that pursue a specific goal - that of breaking regular habits of thinking. These activities have no apparent links whatsoever with the target problem to be solved. Owing to their unusual and counterintuitive nature, such activities prove to be rather challenging for participants who do not see their point inasmuch as there is no direct logical link between the real-life problem they are confronted with and need to find a solution for, and the activities, the domains they are guided into. To enhance the creativity process further, such activities are carried out in multidisciplinary groups, that is, participants have different educational backgrounds and often do not major in the field to which the problem to be solved pertains. This framework, which at first sight is illogical and random, is carefully designed and is voluntary as it ensures a novel standpoint from which the problem is addressed and is intended to circumvent participants' tendency to look for ideas and solutions in habitual domains. 


\subsection{Parallel thinking inside two unrelated boxes: Innovation}

A change in the habit of 'typical' thinking based on experiential results, ignoring what has been possible so far and making hypotheses based on intuition and anticipating what can be possible in the future are all characteristic of innovative thinking. The expression 'breakthrough idea' is insightful in itself as it draws our attention to the central role of marking a break with what is known and what is logical. Breaking the chain of conventional thought and making a leap to get outside the box are requisite for breakthrough ideas to be generated and innovation to become possible. However, getting outside the box is not sufficient. The mind needs to find a new domain (box) to tap into and this is where the role of metaphor is crucial. Metaphor is what enables the mind to draw parallels between two unrelated domains and to come up with maverick ideas.

Innovation does not only require thinking outside the box. Innovative thinking is parallel thinking inside two unrelated boxes. Innovation is going beyond the 'typical' or 'normal' thinking. What is meant by 'normal' is actually logical thinking, thinking that complies with the laws of association and is determined by previous cognition. Innovating is surpassing the known and trespassing the laws of association. Children are believed to be more creative. This is probably because they are not aware of what is known to be possible, of the boundaries of the possible and the impossible. Their thinking is not biased by what has been known so far (cognition). They are not (yet) aware of the box and quite naturally tend to think outside it. As children grow and become adults, social and cultural beliefs along with scientific knowledge gradually build the walls of the box, the barriers that constitute the box inside of which they think from then on. This idea is also put forward in the following quote on creativity commonly attributed to Ursula LeGuin: "The creative adult is the child who survived"4. The importance of creative thinking and its absence in traditional educational approaches is brilliantly illustrated by a well-known TED talk entitled "Do schools kill creativity?" by creativity expert Sir Ken Robinson ${ }^{5}$. This view is also highlighted in a talk entitled "Unteaching uncreativity" that was given to the American Society for Engineering Education by Rolf A. Faste ${ }^{6}$ in the mid-1970s. To enhance innovative ideas, parents and educational system should foster metaphorical reasoning.

4 Wahl, David. 2018. "Surviving blandness" in Creative Creativity, at https://creativecreativity. com/2018/01/27/surviving-blandness/ was accessed on 14 June 2020.

5 Robinson, Ken 2006. “Do schools kill creativity?", TED talk available at https://www.ted. com/talks/sir_ken_robinson_bring_on_the_learning_revolution?language=fr.

6 Faste, Rolf A. Unteaching Uncreativity. A talk given to the American Society for Engineering Education in the mid-1970s, available at <http://www.fastefoundation.org/publications/ unteaching_uncreativity.pdf $>$ was accessed on 27 August 2020. 


\section{Concluding remarks}

The purpose of the present study was to contribute to the understanding of the inner workings of innovative thought. Its conclusions are threefold. Firstly, innovation is intricately linked with metaphor and innovative processes can be analysed in the light of induction. So far, innovation has been treated extensively as abduction, in particular due to its "being the only kind of argument which starts a new idea" (CP 2. 96). However, in view of the above discussion, it can be argued that the basic feature of innovative ideas is not their being new, but their deriving from novel combinations of ideas pertaining to unrelated domains. Furthermore, unlike abduction, which yields hypotheses bearing on particular cases, induction affords inferring a rule and making general hypotheses applicable to future experiences.

Secondly, this study argues that likeness, in Peirce's conception of the term, manifests itself throughout the three modes of reasoning and that a parallel can be drawn between the Peircean triad of hypoicons and the trichotomy of arguments. Therefore, abduction, deduction and induction are based on image, diagram and metaphor, respectively. This parallel can further contribute to grounding the view which favours induction as thirdness, rather than secondness. The major claim of the present paper is that metaphoric representation underlying inductive reasoning is what makes innovative thought possible.

Finally, the arguments developed in the present study lead us to conclude that there is a need for a new perspective on metaphor, which would provide a more extensive account for its symbolic nature and innovative potential.

\section{References}

Anderson, Douglas 1984. Peirce on metaphor. Transactions of the Charles S. Peirce Society 20(4): 453-468.

Aristotle 1961. Poetics. New York: Hill and Wang.

Bergen, Benjamin K. 2012. Louder than Words: The New Science of How the Mind Makes Meaning. New York: Basic Books.

Black, Max 1954-1955. Metaphor. Proceedings of the Aristotelian Society (New Series) 55: 273294. https://doi.org/10.1093/aristotelian/55.1.273

Black, Max 1962. Models and Metaphors: Studies in Language and Philosophy. Ithaca: Cornell University Press. https://doi.org/10.7591/9781501741326

Brown, Tim. 2009. Change by Design: How Design Thinking Transforms Organizations and Inspires Innovation. New York: Harper Business.

Casakin, Hernan P. 2007. Metaphors in design problem solving: Implications for creativity. International Journal of Design 1(2): 21-33.

Casakin, Hernan P. 2013. Metaphorical reasoning and design creativity: Consequences for practice and education. In: Carayannis Elias G. (ed.), Encyclopedia of Creativity, 
Invention, Innovation and Entrepreneurship. New York: Springer, 1260-1267. https:// doi.org/10.1007/978-1-4614-3858-8_436

Casasanto, Daniel; Boroditsky, Lera 2008. Time in the mind: Using space to think about time. Cognition 106(2): 579-593. https://doi.org/10.1016/j.cognition.2007.03.004

CP $=$ Peirce, Charles Sanders 1958[1931-1935].

Davidson, Donald 1978. What metaphors mean. Critical Enquiry 5: 31-47. https://doi. org/10.1086/447971

Fauconnier, Gilles 1985. Mental Spaces: Aspects of Meaning Construction in Natural Language. Cambridge: Cambridge University Press.

Fauconnier, Gilles 1997. Mappings in Thought and Language. Cambridge: Cambridge University Press. https://doi.org/10.1017/CBO9781139174220

Fauconnier, Gilles; Turner, Mark 1998. Conceptual integration networks. Cognitive Science 22: 133-187. https://doi.org/10.1207/s15516709cog2202_1

Fauconnier, Gilles; Turner, Mark 2002. Conceptual Blending and The Mind's Hidden Complexities. New York: Basic Books.

Feist, Gregory J. 1999. Personality in scientific and artistic creativity. In: Sternberg, Robert J. (ed.), Handbook of Creativity. Cambridge, England: Cambridge University Press, 273-296. https://doi.org/10.1017/CBO9780511807916.016

Kelley, Tom; Kelley, David 2013. Creative Confidence. New York: Crown Business.

Lakoff, George 1993. The contemporary theory of metaphor. In: Ortony, Andrew (ed.), Metaphor and Thought. (2nd ed.) Cambridge: Cambridge University Press, 202-251. https://doi.org/10.1017/CBO9781139173865.013

Lakoff, George; Johnson, Mark 1980. Metaphors We Live By. Chicago: University of Chicago Press.

Lakoff, George; Turner, Mark 1989. More than Cool Reason: A Field Guide to Poetic Metaphor. Chicago: University of Chicago Press. https:/doi.org/10.7208/chicago/ 9780226470986.001.0001

Landau, Mark J.; Robinson, Michael D.; Meier, Brian P. (eds.) 2014. The Power of Metaphor: Examining Its Influence on Social Life. Washington: American Psychological Association.

Loewenberg, Ina 1978. Creativity and correspondence in fiction and in metaphor. The Journal of Aesthetics and Art Criticism 36(3) [Critical Interpretation]: 341-350. https:// doi.org/10.1111/1540_6245.jaac36.3.0341

Miller, Arthur I. 1996. Metaphors in creative scientific thought. Creativity Research Journal 9 (2/3): 113-130. https://doi.org/10.1080/10400419.1996.9651167

Osborn, Alex F. 1942. How to Think Up. New York: McGraw-Hill.

Osborn, Alex F. 1953. Applied Imagination: Principles and Procedures of Creative ProblemSolving. New York: Charles Scribner's Sons.

Peirce, Charles Sanders 1958[1931-1935]. The Collected Papers of Charles Sanders Peirce. (Vols. 1-6, Hartshorne, Charles; Weiss, Paul, eds. 1931-1935; vols. 7-8, Burks, Arthur W., ed., 1958.) Cambridge: Harvard University Press. [In-text references are to CP, followed by volume and paragraph numbers.]

Richards, Ivor A. 1936. The Philosophy of Rhetoric. London: Oxford University Press.

Samples, Bob 1976. The Metaphoric Mind: A Celebration of Creative Consciousness. Massachusetts: Addison-Wesley Publishing Company. 
Sanchez-Ruiz, Marie-Jose et al. 2013. The role of metaphorical thinking in the creativity of scientific discourse. Creativity Research Journal 25(4): 361-368. https://doi.org/10.1 080/10400419.2013.843316

Sawyer, Keith 2012[2006]. Explaining Creativity: The Science of Human Innovation. (2nd ed.) Oxford: Oxford University Press.

Searle, John R. 1979. Expression and Meaning: Studies in the Theory of Speech Acts. Cambridge: Cambridge University Press. https://doi.org/10.1017/CBO9780511609213

\section{Метафора, индукция и инновации: выход за рамки}

Сегодня, более чем когда-либо, инновации кажутся жизненно важными для того, чтобы предвидеть и адаптироваться к нашему быстро меняющемуся миру. Но что такое инновация и как ее достичь? Как разум может генерировать инновационные идеи? Для лучшего понимания механизмов, лежащих в основе человеческих возможностей в сфере инновации, в настоящем исследовании поставлена цель ответить на два основных вопроса: 1) что делает инновации возможными? и 2) почему инновационные идеи необычны? Эти вопросы рассматриваются в рамках семиотики Пирса и понятия инференции или умозаключения. В работе изучаются различные типы умозаключений для определения способа рассуждения, который является центральным для инновационной мысли. Хотя креативность и инновации часто анализируются через призму абдукции, в исследовании предлагается альтернативный подход, проводящий параллель между способами умозаключений и типами гипоикон, а также демонстрирующий, как инновации становятся возможными благодаря метафорическому рассуждению, лежащему в основе индукции.

\section{Metafoor, induktsioon ja innovatsioon: kastist välja pääsemine}

Rohkem kui kunagi varem tundub innovatsioon meile tänapäeval vajalikuna, et ümbritsevas maailmas aset leidvateks kiireteks muutusteks valmis olla ja nendega kohaneda. Aga mis on innovatsioon ja kuidas seda täide viia? Kuidas saab mõistus tekitada uuenduslikke ideid? Et paremini mõista mehhanisme, millele toetub inimeste innovatsioonivõime, püütakse käesolevas uurimuses vastata kahele alusküsimusele: esiteks, mis muudab innovatsiooni võimalikuks, ja teiseks, miks on innovatiivsed ideed ebatavalised? Need küsimused võetakse vaatlus alla Peirce’i semiootika raamistusest lähtudes, eriti Peirce'i järelduse mõiste valguses. Vaadeldakse erinevaid inferentsitüüpe, et leida uuendusliku mõtte jaoks keskne arutluslaad. Kui loomingulisust ja innovatsiooni analüüsitakse sageli läbi abduktsiooniprisma, pakutakse selles uurimuses välja alternatiivne lähenemine, mis tõmbab paralleeli inferentsilaadide ja hüpoikoonitüüpide vahele. Väidetakse, et see, mis muudab innovatsiooni võimalikuks, on induktsiooni aluseks olev metafoorne arutlemine. 